\author{
Kanevskii Grigorii \\ Klubnichkin Aleksandr \\ Sazonov Kirill
}

http://dx.doi.org/10.21278/brod71303

ISSN 0007-215X

eISSN $1845-5859$

\title{
PROPULSION PERFORMANCE PREDICTION METHOD FOR MULTI SHAFT VESSELS
}

UDC 629.5.038

Original Scientific Paper

\begin{abstract}
Summary
A method is suggested for estimating the propulsion performance of a multi-shaft vessel. Possibility of applying one total thrust deduction coefficient to all ship shafts is justified and associated issues are discussed. Multi-shaft vessels are generically defined as vessels equipped with different types of propulsive units with non-similar geometry particulars or non-similar operating conditions, if geometry is the same. The paper suggests an iteration algorithm to estimate propulsion ship performance from standard data inputs obtained in model tests. An example of such calculations is given.
\end{abstract}

Key words: $\quad$ multi-shaft ship; icebreaker; model experiment; interaction coefficients; podded propulsor; propeller, calculation; off-design mode

\section{Introduction}

Propulsion performance prediction based on model test data is a part of the ship theory first addressed by William Froude [1] in his publications back in the middle of the 19th century, who introduced the concept of equivalent flat plate and assumption of equal residual resistance coefficient for model and ship. It laid foundation for further in-depth research regarding water resistance to ship motion. William Froude and his son carried out the first experiments on model propellers to study their interaction with ship hull models.

A range of various ship theory aspects related to ship propulsion predictions from model tests were developed further in the 20th century [2]. A notable milestone on this way was the ITTC'78 performance prediction method for single-shaft vessels [3,4]. Ever since, persistent efforts have been continued for further elaboration of this method, for example [5,6], with its fourth revision published in 2017 [7].

One of the recent shipbuilding trends is construction of multi-shaft vessels enabling designers to achieve larger displacements and power/weight ratios within conventional draught constraints. This tendency is reflected in the ITTC Propulsion Committee recommendations regarding triple shaft vessels [8,9]. Unfortunately, these guidelines [9] have been published without prior across-the-board discussions in specialist journals. The purpose of this publication is to develop a method for estimation of multi-shaft vessel propulsion performance. The method suggested here is functional and free from deficiencies of the work [9]. In the authors' opinion, 
the proposed method is a natural extension of the commonly accepted 1978 ITTC method [7] to the multi-shaft vessels.

\section{Multi-shaft vessel definition.}

In shipbuilding a multi-shaft vessel is traditionally understood as a ship propelled with three or more propulsive units. However, analysis of many modern ship designs indicates that this definition is not aligned with practical demands. For the purposes of this study the multishaft ship is understood as a vessel having at least two different types of propulsors. Propulsive units of a multi-shaft ship differ either by geometry particulars or by operating conditions at the same geometry. The ship can be equipped with $\mathrm{N}$ different types of propulsors. The number of units in each propulsor type is specified as $Z_{\mathrm{P} 1}, \ldots, Z_{\mathrm{Pi}}, \ldots, Z_{\mathrm{PN}}$. Then, the total number of propulsor units is $Z_{p}=\sum_{i=1}^{N} Z_{P i}$.

Examples for illustration of the introduced definitions are given below.

A common twin-shaft vessel with two propellers (port \& starboard) is not considered as a multi-shaft ship in this study. However, a similar twin-screw ship having some special hull design features, like moonpool, asymmetrical with respect to the ship centerline, falls into the multi-shaft vessel category. The point is that a moonpool on one of the ship sides would alter the propeller/hull interaction coefficients so that operating conditions for the propulsors would be different. In this example $N=Z_{P}=2 ; \quad Z_{P 1}=Z_{P 2}=1$.

Another case: a propulsive system with one screw propeller on shaft in the CL plane and one azimuthing thruster installed behind the propeller should be treated as a multi-shaft system [10]. Here also we have $N=Z_{P}=2 ; \quad Z_{P 1}=Z_{P 2}=1$.

For a common triple shaft vessel it is $N=2 ; Z_{P}=3 ; Z_{P 1}=1 ; Z_{P 2}=2$.

One of the vivid examples is described in Ref. [11] containing model test data for a port icebreaker Aker ARC 130A equipped with three Azipod units [12], with two thrusters at the stern and one thruster in the bow. Model experiments have provided conclusive evidences that the bow thruster slipstream has a strong effect on one of the stern units and significantly modify flow conditions around the starboard propulsor. Thus, each thruster of this triple shaft vessel has its own individual operating conditions. For the port icebreaker Aker ARC 130A we have $N=Z_{P}=3 ; \quad Z_{P 1}=Z_{P 2}=Z_{P 3}=1$.

A multi-shaft vessel may be outfitted with different types of propulsors of any number. According to usual practice the number of propulsive unit types is $N \leq 3$. All propulsors under consideration here should be amenable to open-water tests to enable evaluation of their hydrodynamic characteristics in isolation from hull. Each propulsive unit is supposed to include a screw propeller.

The approach described below is applicable to any multi-shaft vessel.

\section{Determination of propeller/hull interaction coefficients for a multi-shaft vessel.}

\section{a. Interaction coefficients.}

The propeller/hull interaction coefficients are determined by self-propelled model tests with an additional towing force $F_{D}$. Self-propelled model tests are to be performed at the same shaft-wise power ratios as in full scale. 
Self-propulsion model tests are performed in two stages. The first stage is revolution rate adjustment for propulsors of different types based on several, e.g. four, revolution rates for type 1 propulsors, i.e. $n_{M 1_{-} 1}, n_{M 2_{-} 1}, n_{M 3_{-} 1}, n_{M 4_{-} 1}$, with subsequent trial runs of the model at speed $V_{M}$ intended to adjust revolution rates $n_{M 1_{-} \mathrm{i}}, n_{M 2_{\mathrm{i}}}, n_{M 3_{-} \mathrm{i}}, n_{M 4_{\_} \mathrm{i}}$ for the rest of the propulsors keeping their delivered power ratios $P_{D M_{-} \mathrm{i}} / P_{D M_{-} 1}$ equal to those specified for the full scale. This is easy to achieve by measuring propulsor torque $Q_{M_{-} i}$ and using a well-known formula, $P_{D M_{-} i}=2 \pi n_{M_{-} i} Q_{M_{-} i}$ that yields ratios $n_{M_{-} \mathrm{i}} / n_{\mathrm{M}_{-} 1}=f\left(n_{M_{-} 1}\right)$.

Once revolution rates are adjusted for all the propulsors, the next stage is to perform selfpropulsion model tests with subsequent determination of propeller revolution rate for type 1 propulsors at which traction force of the towing carriage is equal to additional towing force $F_{D}$. After this, revolution rates for other propulsor types $n_{M D} i$ can be calculated as per the obtained ratios for revolution rates of different propulsors.

In the overall analysis of all self-propelled test results the data obtained in the behind conditions and open-water propeller curves are processed using standard procedures recommended by ITTC 1978 [7]. In accordance with these recommendations the total thrust deduction coefficient $t$ is found:

$$
1-t=1-\frac{T_{M}+F_{D}-R_{C}}{T_{M}}=\frac{-F_{D}+R_{C}}{T_{M}}
$$

where $T_{M}$ - total thrust of propulsors; $F_{D}$ - additional towing force; $R_{C}$ - towing resistance of model.

At the same time the analysis of self-propelled model test data provides the values of

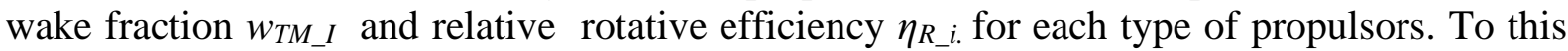
effect, thrust and torque coefficients $K_{T M D_{-} i}$ and $K_{Q M D_{-} i}$ of model propulsors have to be determined for the $i$-th propulsor type. The next step is to calculate the propulsor advance ratio behind the hull as per formula $J_{D_{-} i}=V_{M} /\left(D_{M_{-} i} \cdot n_{M D_{-} i}\right)$. Here, 'D' subscript denotes the condition when towing carriage traction force is equal to additional towing force $F_{D}$. The values of $K_{T M D_{-} i}$ and $K_{Q M D_{-} i}$ for advance ratio $J_{D_{-} i}$ can be added to the plot of open-water model test data for the $i$-th propulsor type. Then it becomes possible, using the standard procedures recommended by ITTC for single-shafters, to find wake fraction $w_{T M_{-} i}$ and relative rotative efficiency $\eta_{R_{-} i}$ for each type of propulsors.

It can be noted that it is preferable to use open-water test data at relatively low revolutions for analysis of self-propelled model test results. These low revolutions should be chosen as close as possible to self-propulsion test conditions. In this case the relative rotative efficiency $\eta_{R_{-} i}$ is close to unity.

\section{b.Total thrust deduction coefficient and partial thrust deduction coefficients.}

Towing resistance $R_{T}$ of three-shafted ships can be calculated as follows:

$$
R_{T}=(1-t) \sum_{i=1}^{3} T_{i}=\left(1-t_{1}\right) T_{1}+2\left(1-t_{2}\right) T_{2}, \quad T_{2}=T_{3}
$$

where $t$ - total thrust deduction coefficient determined from model test data; $t_{1}, t_{2}$ - thrust deduction coefficients of the central and side propellers, respectively; $T_{1}, T_{2}$ - thrusts of central 
and side propellers, respectively. Subscript "1" here and further refers to the central propeller, and subscript " 2 " to side propellers. It is supposed that side propellers have the same hydrodynamic characteristics.

Eq. (2) can be used to express the mutual relationship of partial coefficients $t_{1}, t_{2}$ :

$$
t_{1}=1-(1-t)\left(1+\frac{2 T_{2}}{T_{1}}\right)+\left(1-t_{2}\right) \frac{2 T_{2}}{T_{1}} .
$$

Eq. (3) specifies a certain straight line in the coordinates $t_{1}, t_{2}$ of partial thrust deduction coefficients. This line can be obtained by giving various values to $t_{2}$ at constant $t, T_{1} \& T_{2}$ and by calculating corresponding values of $t_{1}$. Any pair of the partial coefficients belonging to this straight line provides the same towing resistance (total effective thrust) of the vessel. It should be noted that among possible pairs of partial coefficients we always have the following pair $t_{1}=t_{2}=t$. It can be proven by direct substitution into Eq. (3). For this reason the total thrust deduction coefficient should enable correct estimation of ship's towing resistance (total effective thrust) in propulsion performance calculations. In this connection the authors believe it no advisable to introduce a concept of "partial thrust deduction coefficients".

\section{c.Scale effect of wake fraction.}

In [9] for taking account of the scale effect the formula for wake fraction is used, which is proposed in [7] and derived for single shaft vessels and then adapted to the twin shaft vessels. This formula is as follows:

$$
w_{T S}=\left(t+w_{R}\right)+\left(w_{T M}-t-w_{R}\right) \frac{(1+k) C_{F S}+\Delta C_{F}}{(1+k) C_{F M}}
$$

where $w_{T S}, w_{T M}$ - wake fraction of ship and model, respectively; $w_{R}$ - coefficient for rudder effect on wake fraction, if there is no rudder behind propeller, then $w_{R}=0 ; k$ - form factor; $C_{F S}, \mathrm{C}_{F M}$ - friction coefficient for ship and model, respectively, calculated based on equivalent plate; $\Delta C_{F}$ - roughness allowance.

Formula (4) is far from perfect and has long been criticized by researchers. At the time when this formula was derived the single-shaft merchant vessels used to have V- or U-shaped stern frames. It was presumed that propulsion performance could be improved by increasing the wake fraction. At present the merchant vessels are mainly designed with the buttock-flow stern resulting in lower towing resistance and drastic reduction in wake fraction. The wake fraction has become lower than the thrust deduction $t$. In these cases Eq. (4) gives paradox results when the full-scale wake fraction is higher than in model conditions. It follows directly from Eq. (4): at $w_{R}=0, w_{T S} \geq w_{T M}$, if $t \geq w_{T M}$. For avoiding such unrealistic results Ref. [13] suggests to apply a "provisional measure" assuming that $w_{T S}=w_{T M}$, if $w_{T S}<w_{T M}$.

To overcome these difficulties it is required to estimate the scale effect from formulae that do not include the thrust deduction coefficient. An example of such formulae is given below. It is derived from test data obtained for models with increased hull roughness [14].

$$
\frac{w_{T S}}{w_{T M}}=0.4+0.6 \frac{C_{V S}}{C_{V M}},
$$

where $C_{V}$ - coefficient of viscous resistance due to friction of hull plating. 
Analysis of experimental results and computer calculations [15], as well as practical experience confirm that Eq.(5) is workable and provides satisfactory accuracy of results for practical applications.

For multi-shaft case

$$
\frac{w_{T S_{-} i}}{w_{T M_{-} i}}=0.4+0.6 \frac{C_{V S}}{C_{V M}} .
$$

Knowing the propeller-hull interaction coefficient $\mathrm{t}, w_{T S_{-} i}, \eta_{R i}$, open-water characteristics of propulsors $K_{T S_{-} i}, K_{Q S_{-} i}$ and towing resistance of vessel $R_{T S}$ one can pass to propulsion performance estimations for the multi-shaft vessel.

\section{Propulsion prediction method.}

The main idea of the proposed method is that the thrust deduction coefficient is not divided between shafts, but a total thrust deduction coefficient is applied, which is estimated from self-propelled model test data. Therefore, the following relation can be written, which is based on the obvious equality between the ship's total effective thrust $T_{E}$ and resistance of water to ship motion $R_{T S}$ :

$$
R_{T S}=(1-t) \sum_{i=1}^{N} Z_{P i} T_{i},
$$

where $R_{T S}$ - ship resistance at given speed $V_{S} . T_{i}$ thrust of $i$-th propulsor. It should be noted that the term of effective thrust $T_{E_{-} i}$ means effective part of thrust.

$$
T_{E_{-} i}=(1-t) T_{i}
$$

For further reasoning we need to know the fractions of thrust of each type of propulsors $\kappa_{i}$ expressed as:

$$
\kappa_{i}=\frac{T_{i}}{\sum_{i=1}^{N} Z_{P i} T_{i}} .
$$

The initial data inputs for this method are ships' hydrodynamic resistance, hull/propeller interaction coefficients and open-water propeller curves found from model tests and extrapolated to full scale for a given ship speed $V_{S}$.

Calculations are performed based on the iterative procedure using the thrust load coefficient $K_{T_{-} i} / J_{i}^{2}$, making it possible to meet the specified law of delivered power distribution by shafts of a multi-shaft vessel. Theoretically, the power distribution by shafts can be arbitrary. However, the same power is delivered to propulsors of the same type. The symbol $m_{i}$ denotes fractions of the total power delivered to each propulsor of the $i$-th type. The values of these fractions are defined by:

$$
m_{i}=\frac{P_{D S_{\_} i}}{\sum_{i=1}^{N} Z_{P i} P_{D S_{-} i}},
$$

where $P_{D S_{-} i}$ - power delivered to each propulsor of the $i$-th type. 
These fractions are constrained by $m_{i}<1$ and $\sum_{i=1}^{N} Z_{P i} m_{i}=1$. E.g., when the power is uniformly spread between three shafts, we have $m_{i}=1 / 3$. At the distribution law 1:2:1, $m_{1}=0.5$, while $m_{2}=0.25 \quad(1-$ central propeller, $2-$ side propellers $)$.

The following relation can be written for each type of propulsors

$$
\frac{K_{T S_{-} i}}{J_{i}^{2}}=\frac{S_{S}}{2 D_{S_{-} i}^{2}} \frac{C_{T S} \kappa_{i}}{(1-t)\left(1-w_{T S_{-} i}\right)^{2}},
$$

where $K_{T S_{-} i}$ - thrust coefficient of $i$-th propulsor type; $J_{i}$ - open water advance coefficient of $i$-th propulsor type; $D_{S_{-} i}$ - diameter of $i$-th propulsor type; $S_{S}$ - ship hull wetted surface; $C_{T S}$ - ship resistance coefficient; $w_{T S_{-} i}-$ wake fraction of $i$-th propulsor type.

The initial approximation of iteration process is

$$
\kappa_{i}=m_{i}
$$

In this case it is supposed that the thrust of propulsors is distributed in accordance with the delivered power ratio.

Eq.(11) can be used to find the revolution rate $n_{S_{-} i}^{(0)}$, consumed power $P_{D S_{-} i}^{(0)}$ and thrust $T_{S_{-} i}^{(0)}$ for each $i$-th propulsor type at the initial iteration step.

$$
\begin{aligned}
& n_{S_{-} i}^{(k)}=\frac{\left(1-w_{T S_{-} i}\right) V_{S}}{\left(J_{T S_{-} i}^{2}\right)^{(k)} D_{S_{-} i}}, \\
& P_{D S_{-} i}^{(k)}=2 \pi \rho_{S} D_{S_{-} i}^{5}\left(n_{S_{-} i}^{3}\right)^{(k)} \frac{K_{Q T S_{-} i}^{(k)}}{\eta_{R_{-} i}} \cdot 10^{-3}, \\
& T_{S_{-} i}^{(k)}=\left[\frac{K_{T S_{-} i}^{(k)}}{\left(J_{i}^{2}\right)^{(k)}}\right]\left(J_{T S_{-} i}^{2}\right)^{(k)} \rho_{S} D_{S_{-} i}^{4}\left(n_{S_{-} i}^{2}\right)^{(k)},
\end{aligned}
$$

where $K_{Q T S_{-} i}$ - torque of $i$-th propulsor type; $J_{T S_{-} i}$ - advance ratio of $i$-th propulsor type behind ship hull; $k$ - iteration number. It should be noted that the obtained thrust values comply with the introduced values of $\kappa_{i}$. It is also noted that the obtained specific power values do not comply with the introduced values of $m_{i}$.

Then, let us use the results of initial iteration and all subsequent iterations for $P_{D S_{-} i}$ values to find $\kappa_{i}$ values at the next iteration

$$
m_{i}^{(k)}=\frac{P_{D S_{-} i}^{(k)}}{\sum_{i=1}^{N} Z_{P i} P_{D S_{-} i}^{(k)}} .
$$




$$
\kappa_{i}^{(k+1)}=\kappa_{i}^{(k)} \frac{m_{i}}{m_{i}^{(k)}}
$$

Then, the next iteration is calculated starting from Eq. (11).

The iteration process is completed when $m_{i} \approx m_{i}^{(k)}$ for all $i$ with a given accuracy.

\section{Case study.}

The proposed method is applied to calculate propulsion performance of a shallow-water icebreaker. The principal dimensions of this vessel are given in Table 1.

Table 1 - Geometry particulars of shallow-water icebreaker

\begin{tabular}{|l|l|l|}
\hline Length between perpendiculars, $\mathrm{L}_{\mathrm{pp}}$ & $\mathrm{m}$ & 140.0 \\
\hline Beam at mid-length, B & $\mathrm{m}$ & 29.8 \\
\hline Draft at bow , $\mathrm{T}_{\mathrm{F}}$ & $\mathrm{m}$ & 8.5 \\
\hline Draft at stern, $\mathrm{T}_{\mathrm{A}}$ & $\mathrm{m}$ & 8.5 \\
\hline Volume displacement, $\nabla$ & $\mathrm{m}^{3}$ & 21233.6 \\
\hline
\end{tabular}

The ship is equipped with two side screw propellers in bossings and one pulling podded thruster in the middle. Diameter of all three propellers is $5.3 \mathrm{~m}$. A ship model was made to $\lambda$ $=26.5$ scale to perform the entire cycle of traditional model experiments. Fig. 1 shows a photo of the icebreaker model stern.

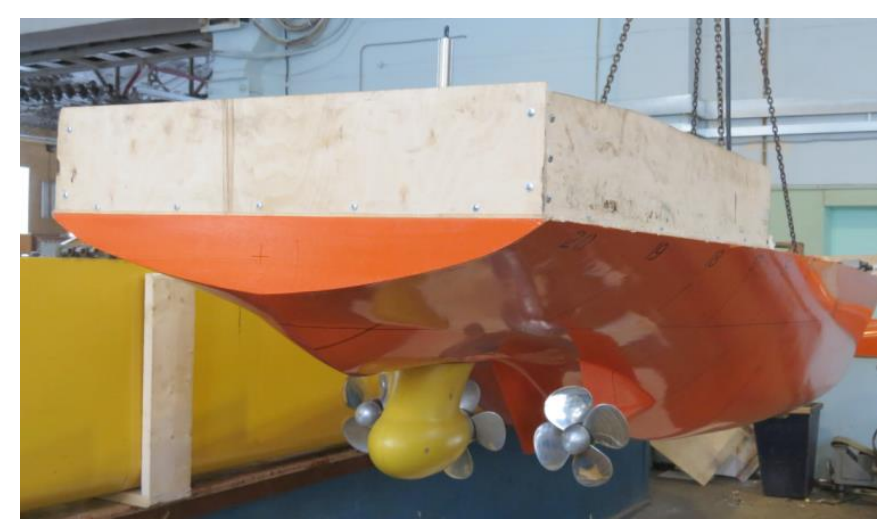

Fig. 1 Stern of shallow-water icebreaker model: General view.1

In this case the number of propulsor types is $N=2$. First type: podded thruster in the middle $Z_{P 2}=1$. Second type: side screw propeller $Z_{P 1}=2$. Total number of propulsors: $Z_{P}=3$. Efficiency of electro-mechanical transmission: $\eta_{\mathrm{sh}_{1}}=0.94, \eta_{\mathrm{sh}_{2}}=0.98$. Power consumed by propulsors $P_{D 1}=3290 \mathrm{~kW}, P_{D 2}=3430 \mathrm{~kW}$.

Fig.2 shows the curve of towing resistance $R_{T_{-} S}$ versus ship speed $V_{S}$. 


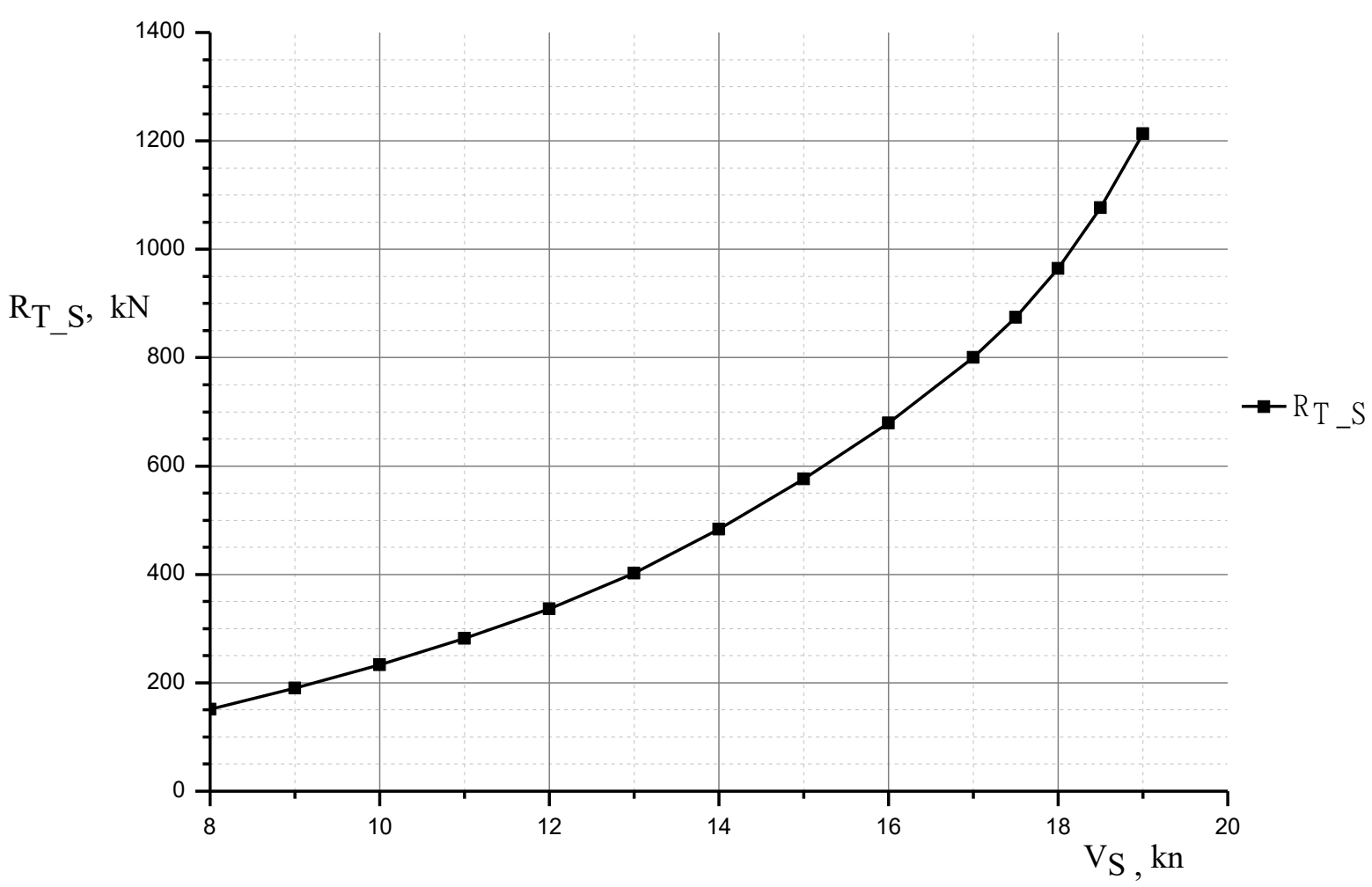

Fig. 2 Towing resistance $R_{T_{-}}$versus ship speed $V_{S}$.

The sea water density was assumed $\rho_{S}=1025 \mathrm{~kg} / \mathrm{m}^{3}$.

Hydrodynamic characteristics of the podded thruster are shown in Fig.4, and hydrodynamic characteristics of side propeller are given in Fig. 3.

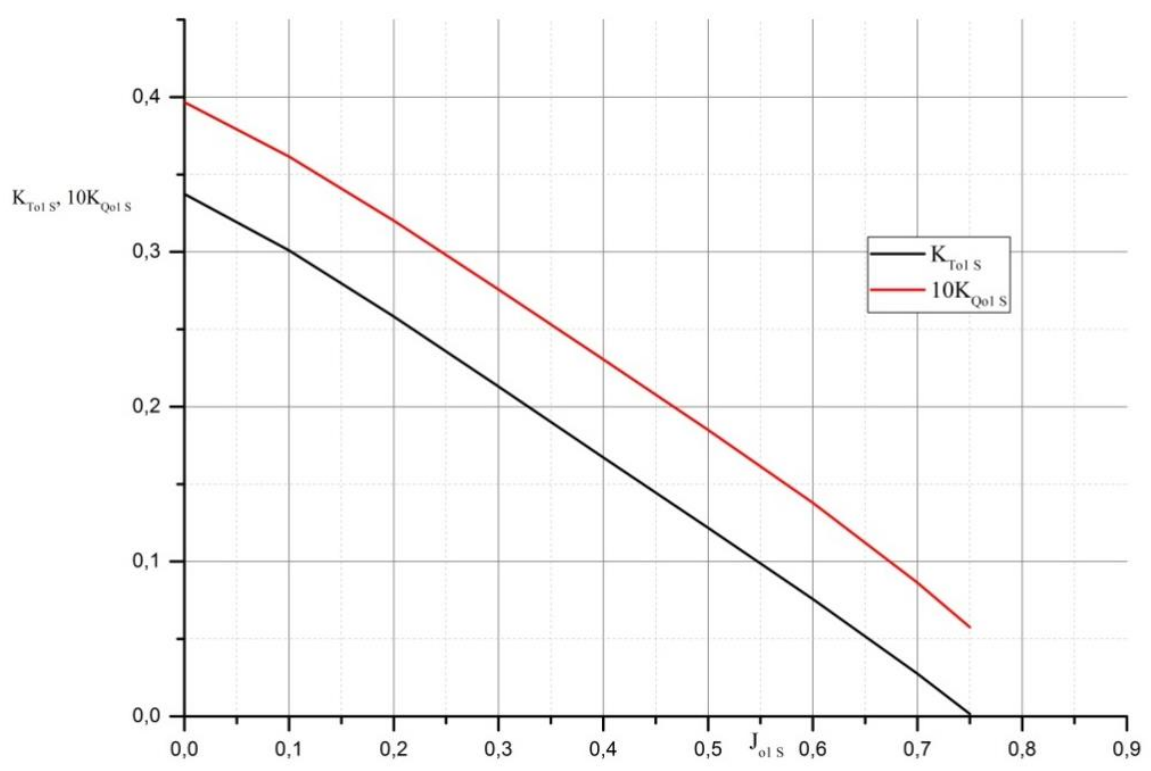


Fig.3 Hydrodynamic characteristics of side propeller.

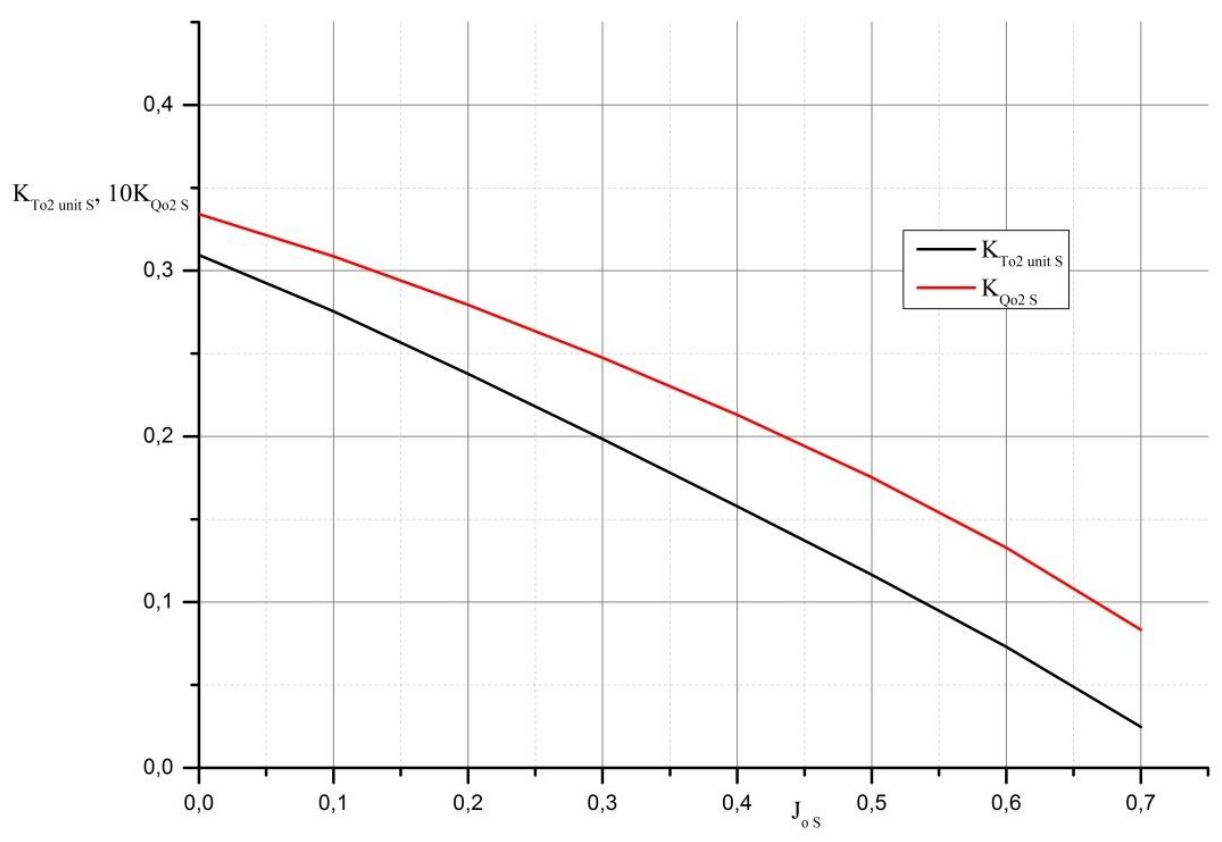

Fig.4 Hydrodynamic characteristics of podded thruster (central).

Calculations are performed for the ship speed $V_{S}=15.35$ knots for the following hull/propeller interaction coefficients:

1. Total thrust deduction coefficient $\mathrm{t}=0.131$.

2. Wake fraction $w_{T 1_{-} S}=0.093, w_{T 2_{-} S}=0.086$.

3. Relative rotative efficiency $\eta_{R_{-} l}=0.962, \eta_{R_{-} 2}=1$.

The following characteristics of the icebreaker performance in deep water were derived using the above-described algorithm:

1. Rate of revolutions $n_{1 S}=128.77 \mathrm{RPM}, n_{2}=130.22 \mathrm{RPM}$.

2. Thrust of propulsors $T_{1 S}=220.8 \mathrm{kN}, \mathrm{T} 2{ }_{S}=240.68 \mathrm{kN}$.

3. Propeller torque $Q_{1 S}=244.0 \mathrm{kN} * \mathrm{~m}, Q_{2 S}=251.6 \mathrm{kN} * \mathrm{~m}$.

4. Effective thrust of propulsors $T_{E 1 S}=191.9 \mathrm{kN}, T_{E 2 S}=209.1 \mathrm{kN}$.

5. Hull efficiency $\eta_{H 1 S}=0.922, \eta_{H 2 S}=0.951$.

6. Propulsive efficiency of propulsors $\eta_{1 s}=0.433, \eta_{2} s=0.472$.

7. Propulsive efficiency of propulsion system $\eta_{S}=0.459$.

The 3 iterations were required for calculations.

The suggested method has also been successfully applied to predict propulsion performance of other vessels, e.g. a port icebreaker of Aker ARC 130A type [11]. As of today, two icebreakers of this design have passed sea trials:

1. IMO 9734161, Polaris, port of registration - Helsinki,

2. IMO 9777101, Alexander Sannikov, port of registration - St. Petersburg.

This design practice is widely introduced in Russia already. E.g., this approach has been used to estimate propulsion performance of the third-generation nuclear icebreakers under construction (lead ship Arktika), as well as in the design of a prospective 120MW icebreaker (Leader). 


\section{Conclusion.}

The paper suggests a new approach to performance prediction of multi-shaft vessels. A generic definition of multi-shaft vessels is given to enable common ground for treatment of multi-shaft vessels. The algorithm suggested for multi-shaft vessels is based on application of a total thrust deduction coefficient. The reasons of this approach are provided in the paper. One total thrust deduction coefficient makes it possible to resolve a number of problems and avoid additional model tests.

A solution is suggested how the scale effect on wake fraction should be taken into account for different types of propulsors in multi-shaft vessels.

The propulsion performance prediction algorithm suggested here for multi-shaft vessels is easily implementable. It is based on standard data obtained from model tests and can be recommended for use.

\section{REFERENCES}

[1] The papers of William Froude. London, The Institute of Naval Architects, 1955, $360 \mathrm{p}$.

[2] Van Lammeren W.P.A., Troost L., Koning G Resistance, Propulsion And Steering Of Ship. The technical publishing company H. Stam-Haarlem-Holland. 1957.

[3] Report of Performance Committee. 15th ITTC Proceedings. Hague, 1978.

[4] ITTC - Recommended Procedures and Guidelines. Performance, Propulsion 1978 ITTC Performance Prediction Method. 7.5-02-03-01.4. 2008, 9 p.

[5] Vlasic D., Degiuli N., Farkas A., Martic I. The Preliminary Design of a Screw Propeller by Means of Computational Fluid Dynamics. //Brodogradnja, 2018, vol. 69, issue 3, pp. 129-147. https://doi.org/10.21278/brod69308

[6] Farkas A., Degiuli N., Martic I. Numerical Simulation of Viscous Flow around a Tanker Model. //Brodogradnja, 2017, vol. 68, issue 2, pp. 109-125. https://doi.org/10.21278/brod68208

[7] ITTC - Recommended Procedures and Guidelines. Performance, Propulsion 1978 ITTC Performance Prediction Method. 7.5-02-03-01.4. 2017, 15 p.

[8] The Propulsion Committee. Final Report and Recommendations to the 28th ITTC. 28th International Towing Tank Conference. Proceedings, Wuxi, China. September 17 -22, 2017. Volume 1 pp. 69-129.

[9] ITTC - Recommended Procedures and Guidelines. Performance Prediction Method for Triple Shaft Vessels. 7.5-02-03-01.7. 2017, 7 p.

[10] The Propulsion Committee. Final Report and Recommendations to the 27th ITTC. 27th International Towing Tank Conference. Proceedings, 2014, Denmark, Copenhagen. Volume 1. pp. 69-129.

[11] Shchemelinin L., Malikov A., Saisto I., Nerman A. Multiple propulsion unit on icebreaker performance in open water and ice condition. Proceedings of the 5th International Symposium on Marine Propulsors. SMP'17 Volume 2, pp. 404- 408, Espoo, Finland, 12-15 June, 2017

[12] Design IBSV01, type Aker ARC 130A. http://fleetphoto.ru/projects/4404/

[13] ITTC - Recommended Procedures and Guidelines, 1978 ITTC Performance Prediction Method. 75-0203-01.4, 1987

[14] Denisov W.I., Pashin V.M., Tumashik A.P. Investigation into the influence of ship hull roughness and scale effect upon hull-propeller interaction // Proceedings of Fourth international symposium on PRADS. Varna, 1989.

[15] Bagaev D.V., Lobachev M.P., Ovchinnikov N.A. Scale effect of propeller/hull interaction coefficients. RANS-based estimations // Transactions of Krylov Shipbuilding Institute. 2012. Issue 69 (353). pp. 5972. (in Russian)

Submitted: $\quad$ 26.09.2019. Sazonov Kirill, Corresponding author, kirsaz@ rambler.ru

Accepted: $\quad 06.08 .2020$. Kanevskii Grigorii, Klubnichkin Aleksandr 